\title{
Creatinine, Urea and Uric Acid in Hospitalized Patients with and Without Hyperglycemia Analysis using Generalized Additive Model
}

\author{
Souad Bechrouri, Abdelilah Monir, Hamid Mraoui, Mohamed Choukri, Ennouamane Saalaoui \\ Department of Chemistry, Mohamed First University, Oujda, Morocco \\ choukrimohamed@hotmail.com;souad.bechrouri@gmail.com, abdelilah.monir@gmail.com, \\ hamid_mraoui@yahoo.fr; saalaoui_ennouamane@yahoo.fr
}

\begin{abstract}
Hyperglycemia is an important risk factor for heart disease and premature mortality. In hospitalized patients, it is related to an increase in morbidity and development of other disease like kidney disease. To evaluate the existent relation between hyperglycemia and different biochemical parameters, we have proceeded to analyzi the difference between groups of patients which are separated according to the Glucose critical value (1.26 g/L). Generalized additive models (GAM) was used in the aim to model the relation between estimated glomerular filtration renal (eGFR) and some biochemical parameters. Our study was conducted on a data set recorded on 5600 hospitalized patients in CHU Oujda. Our statistical study revealed that the hyperglycemic patients present an increase in values of each of uric acid, creatinine, urea and triglycerides. This increase is accompanied by a loss in HDL cholesterol and eGFR. Regarding the gender of patients, results show a difference between males and females according to each of parameters: creatinine, urea, uric acid, total cholesterol, HDL and LDL cholesterol. Moreover, results show lower values of eGFR for males. The model which explain the eGFR shows a non-linear relation between dependent variable eGFR and some predictors (e.g. urea, calcium and uric acid parameters).
\end{abstract}

Keywords-component; hyperglycemia; eGFR; generalized additive model;

\section{Introduction}

Hyperglycemia is considered as an important risk factor for heart disease, even for levels under those currently used to diagnose diabetes. More specifically in hospitalized patients, hyperglycemia is related to an increase in morbidity, hospital stays and the risk of death [1]. Currently around 415 million in the world have diabetes and $\mathbf{3 1 8}$ million of adults have an impaired glucose tolerance (i.e. adults who have blood glucose levels higher than normal but not sufficiently to be classified as diabetics) which expose them to a high risk for developing diabetes in the future [2]. The time lived from the beginning of diabetes 2 and its discover is on average 10 years, a period in which some complications can be developed such as renal disease[3], [4]. The World Health Organization (WHO) estimates that high level blood glucose is one of the important risk factors for premature mortality. This pathology continues to increase in number and importance in parallel with Economic development and change in lifestyles characterized by a reduced physical activity and increased obesity [2]. According to the IDF atlas [2], the highest prevalence was in 
Souad Bechrouri, Abdelilah Monir, Hamid Mraoui, Mohamed Choukri, Ennouamane Saalaoui. Creatinine, Urea and Uric Acid in Hospitalized Patients with and Without Hyperglycemia Analysis using Generalized Additive Model. Transactions on Machine Learning and Artificial Intelligence, Vol 5 No 4 August (2017); p: 403-410

2011 in the Middle East and North Africa (12.5\%). Around \pm 35.4 million people are living with diabetes in the Middle East and North Africa in 2015. Over $40.6 \%$ of them are undiagnosed. The prevalence in this region is estimated at $\pm 9.1 \%$. In Morocco, the prevalence of diabetes has increased to $7 \%$ due to a change in the lifestyle and diminution of physical activity [5]. The majority of diabetics have type 2 diabetes mellitus [6].

Diabetic Kidney disease is one of the important consequence of hyperglycemia. One third of diabetic patients have this complication[7].

The main objective of this work is to study some biochemical parameters in hospitalized patients. We also aim at determining levels of uric acid, urea, creatinine, cholesterol, HDL cholesterol, LDL cholesterol and triglyceride in this population. In the same way, we investigate the correlation between these variables. In addition, we search the effect of dysglycemia and others biochemical parameters on eGFR.

\section{Materials and methods}

\subsection{Sampling procedure}

From October 2015 to Jun 2016, data were recorded from hospitalized patients at the Mohamed VI Hospital Center (CHU) in Morocco. Our data set is constructed from measures recorded on 5600 patients who visited the Hospital in the period of our study. In this work, we select and include patients who have a valid value for fasting blood glucose (FBG). We excluded all patients who have a large percentage of missing data. In the final, the population selected for this study is composed of 4011 patients (where 2025 are males). Hyperglycemia is identified by a Fasting Blood Glucose FBG value greater than $1.26 \mathrm{~g} / \mathrm{L}$. This study is conducted under anonymous and refereeing only on the biochemical characteristic, gender and age.

\subsection{Data Collection}

Data were recorded in the first admission of patient to one of the $\mathrm{CHU}$ services. The data includes demographic information as sex and age. Additionally, we have 15 laboratory tests including fasting blood glucose, creatinine, urea, uric acid, fasting blood total cholesterol, triglyceride and others. Blood samples were analyzed in the $\mathrm{CHU}$ for all laboratory tests. The definition of hypercreatininemia, hyperuremia, hyperuricemia, hypercholesterolemia, hyperHDLemia, hyperLDLemia and hypertriglycerimia is based on the rules below: plasma glucose: for both males and females $0.70-1.10 \mathrm{~g} / \mathrm{L}$, plasma uric acid: Males 30 à $70 \mathrm{mg} / \mathrm{L}$, Females 25 à $60 \mathrm{mg} / \mathrm{L}$; plasma creatinine: Males 6 à $12 \mathrm{mg} / \mathrm{L}$, Females 5 à $10 \mathrm{mg} / \mathrm{L}$; plasma urea: for both males and females 0,15 à $0,45 \mathrm{~g} / \mathrm{L}$; plasma triglyceride: 0,45 à 1,50 g/L ; plasma total cholesterol : 1,50 à $2 \mathrm{~g} / \mathrm{L}$; plasma HDL cholesterol: 0,50 à $0,70 \mathrm{~g} / \mathrm{L}$ and plasma LDL cholesterol: 1 à 1,6 g/L.

\subsection{Statistical analysis}

Data were analyzed under the statistical $R$ software, version 3.2.3. The Wilcoxon test (respectively the Student t-test) were used for mean's comparison for non-Gaussian (and Gaussian) variables. For nominal variables, Fisher's exact test was used for determining differences between groups. The correlation coefficient were analyzed by Spearman correlation analysis. The Glomerular filtration rate (eGFR) is estimated by Modification of Diet in Renal Disease MDRD 2006 function as presented in Eq. (1):

$175 \times \mathrm{SCr}^{-1.154} \times \mathrm{Age}^{-0.203} \times 0.742$ if female 
where $\mathrm{SCr}$ is the Serum Creatinine level.

To search the impact of Fasting Blood Glucose and other biochemical parameters on estimated GFR, we request the use of generalized additive models [8]. The model to estimate is:

$$
E\left(Y \mid X_{1}, \ldots, X_{p}\right)=f_{0}+\sum_{i=1}^{p} f_{i}\left(X_{i}\right)
$$

where $Y$ represents the estimated GFR, $X_{i}$ are the different predictors and $f_{i}$ is an unspecified function. The last one is estimated by natural cubic spline.

Natural cubic splines are piecewise cubic polynomial functions with first and second continuous derivatives at the knots (break points) and zero first and second derivative functions at the boundary knots.

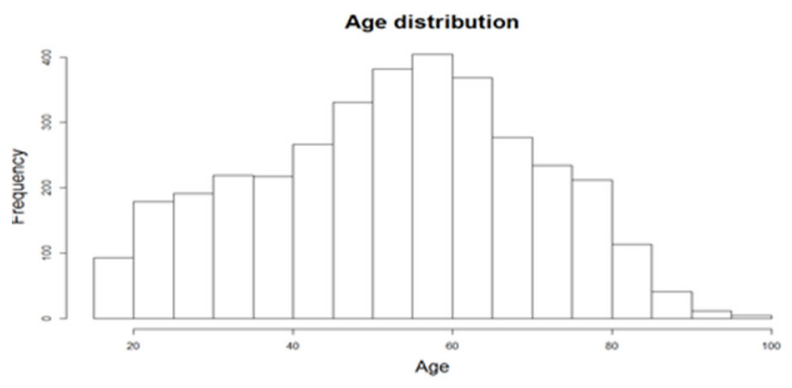

Figure 1. Participants distribution age

Table I. Biochemical Characteristics in the Population of Study

\begin{tabular}{|c|c|c|c|c|}
\hline Characteristics & Total population & glycaemia >=1.26 & glycaemia $<1.26$ & p_value \\
\hline $\mathrm{N}(\%)$ & 3542 & $1107(31.25 \%)$ & $2435(68.75 \%)$ & \\
\hline Age (years) & $52.99( \pm 17.38)$ & $58.81( \pm 15.61)$ & $50.35( \pm 17.51)$ & $<0.0001$ \\
\hline Male (\%) & $1763(49.77 \%)$ & $569(51.92 \%)$ & $1187(48.75 \%)$ & 0.1535 \\
\hline Glucose (g/L) & $1.29( \pm 0.68)$ & $1.98( \pm 0.82)$ & $0.93( \pm 0.17)$ & $<0.0001$ \\
\hline Creatinine (mg/L) & $14.87( \pm 24.21)$ & $18.9( \pm 27.96)$ & $12.95( \pm 21.75)$ & $<0.0001$ \\
\hline Uric acid (mg/L) & $56.11( \pm 25.53)$ & $61.39( \pm 29.85)$ & $53.54( \pm 22.73)$ & $<0.0001$ \\
\hline urea $(\mathrm{g} / \mathrm{L})$ & $0.53( \pm 1.08)$ & $0.65( \pm 0.56)$ & $0.47( \pm 1.23)$ & $<0.0001$ \\
\hline total cholesterol (g/L) & $1.72( \pm 0.58)$ & $1.75( \pm 0.64)$ & $1.71( \pm 0.56)$ & 0.445 \\
\hline HDL cholesterol (g/L) & $0.41( \pm 0.15)$ & $0.38( \pm 0.14)$ & $0.42( \pm 0.15)$ & $<0.0001$ \\
\hline LDL cholesterol (g/L) & $1.04( \pm 0.44)$ & $1.04( \pm 0.48)$ & $1.04( \pm 0.42)$ & 0.4983 \\
\hline triglyceride $(\mathrm{g} / \mathrm{L})$ & $1.39( \pm 1.05)$ & $1.65( \pm 1.26)$ & $1.27( \pm 0.91)$ & $<0.0001$ \\
\hline eGFR $\left(\mathrm{ml} / \mathrm{min} .1 .73 \mathrm{~m}^{2}\right)$ & $101.4(46.32)$ & $84.43(45.11)$ & $100.64(46.58)$ & $<0.0001$ \\
\hline
\end{tabular}

where $\mathrm{SCr}$ is the Serum Creatinine level

\section{Results}

3542 patients aged between 18 and 96 years were included in this study and were hospitalized in CHU (Fig 1). In average, the age of this population is $52.99 \mathrm{y}( \pm 17.38 \mathrm{y}) .50 .22 \%$ of them are females (1779) and $49.77 \%$ are males (1763). Their mean age is 53.05 y ( \pm 17.12 y) and 52.93 y ( \pm 17.65 y) respectively. 1096 patients have a fasting blood glucose upper than $1.26 \mathrm{~g} / \mathrm{L}$. The mean age for this sub-population is 58.84 y ( \pm 15.52 y). 569 (51.92 \%) of them are males and 527 (48.08\%) females. They are aged in mean $57.88 \mathrm{y}$ $( \pm 15.92 \mathrm{y})$ and $59.88 \mathrm{y}( \pm 15.01 \mathrm{y})$ respectively. 408 patients who have plasma glucose between $1.10 \mathrm{~g} / \mathrm{L}$ and $1.26 \mathrm{~g} / \mathrm{L}$ are aged $55.09 \mathrm{y}( \pm 16.76 \mathrm{y})$. 
Souad Bechrouri, Abdelilah Monir, Hamid Mraoui, Mohamed Choukri, Ennouamane Saalaoui. Creatinine, Urea and Uric Acid in Hospitalized Patients with and Without Hyperglycemia Analysis using Generalized Additive Model.

Transactions on Machine Learning and Artificial Intelligence, Vol 5 No 4 August (2017); p: 403-410

Table I summarizes the baseline biochemical analysis by hyperglycemia status. Patients with hyperglycemia were significantly older than those who have a plasma glucose level under than $1.26 \mathrm{~g} / \mathrm{L}$ (58.81y $( \pm 15.61$ y) vs 50.35 y $( \pm 17.51$ y) respectively). The two groups have a significant difference between plasma levels of glucose, uric acid, urea and creatinine. These values are more important in hyperglycemic group. HypoHDLemia was more important in the hyperglycemic group. The total cholesterol and LDL cholesterol are non-significantly different between the two groups. However, for triglyceride levels, it was greater in the first group with $1.62 \mathrm{~g} / \mathrm{L}(( \pm 1.26 \mathrm{~g} / \mathrm{L})$. All these differences were significant at $95 \%$ confidence level. In addition, the GFR value estimated in hyperglycemic group is significantly less than this estimated in the other group $(p<0.0001)$.

The correlation coefficients between different measured parameters are presented in table II. The Age is significantly correlated with creatinine, uric acid and urea $(p<0.005)$. Also, the FBS is positively related with creatinine, urea and negatively related with eGFR. The correlation is significantly negative between the creatinine and different forms of cholesterol and significantly positive between creatinine and both urea, uric acid. Urea and uric acid are strongly correlated with each other and with GFR.

Table 2 Correlation Table Between Measured Variables in Hyperglycemic Group

\begin{tabular}{|c|c|c|c|c|c|c|c|c|}
\hline & Age & FBS & Creatinine & $\begin{array}{l}\text { Uric } \\
\text { acid }\end{array}$ & Urea & $\begin{array}{c}\text { Total } \\
\text { cholesterol }\end{array}$ & $\begin{array}{c}\text { HDL } \\
\text { cholesterol }\end{array}$ & $\begin{array}{c}\text { LDL } \\
\text { cholesterol }\end{array}$ \\
\hline Age & 1 & & & & & & & \\
\hline FBS & 0.02 & 1 & & & & & & \\
\hline Creatinine & $0.24 * * *$ & $0.17 * * *$ & 1 & & & & & \\
\hline Uric acid & $0.15 * *$ & 0.05 & $0.69 * * *$ & 1 & & & & \\
\hline Urea & $0.25 * * *$ & $0.14 * * *$ & $0.78 * * *$ & $0.68 * * *$ & 1 & & & \\
\hline $\begin{array}{l}\text { Total } \\
\text { cholesterol }\end{array}$ & -0.08 & 0.05 & $-0.16^{* * *}$ & -0.10 & $\begin{array}{c}- \\
0.17^{* * *}\end{array}$ & 1 & & \\
\hline $\begin{array}{l}\mathrm{HDL} \\
\text { cholesterol }\end{array}$ & 0.03 & -0.04 & $-0.18 * * *$ & $-0.18 * *$ & $\begin{array}{c}- \\
0.19 * * *\end{array}$ & $0.48 * * *$ & 1 & \\
\hline $\begin{array}{l}\mathrm{LDL} \\
\text { cholesterol }\end{array}$ & -0.06 & 0.02 & $-0.17 * * *$ & -0.11 & $-0.16 * *$ & $0.91 * * *$ & $0.38 * * *$ & 1 \\
\hline Triglyceride & -0.02 & $0.11^{*}$ & 0.06 & $0.15^{* *}$ & 0.03 & $0.46 * * *$ & $-0.17 * * *$ & $0.28 * * *$ \\
\hline eGFR & $\begin{array}{c}- \\
0.36^{* * *}\end{array}$ & $\begin{array}{c}- \\
0.18^{* * *}\end{array}$ & $-0.92 * * *$ & $\begin{array}{c}- \\
0.69 * * *\end{array}$ & $\begin{array}{c}- \\
0.75^{* * *}\end{array}$ & $0.12 * *$ & $0.10^{*}$ & $0.11 *$ \\
\hline
\end{tabular}

Significance levels: $*:<0.05, * *:<0.005, * * *:<0.0005$

Table III represents a comparison of various measured variables according to the gender. Females presented a high fasting glucose level $(2.03 \mathrm{~g} / \mathrm{L}( \pm 0.92))$ than males $(1.92 \mathrm{~g} / \mathrm{L}( \pm 0.73))$. Also, it seems that they have a higher level of plasma cholesterol $(1.84 \mathrm{~g} / \mathrm{L}( \pm 0.67)$ vs $1.67 \mathrm{~g} / \mathrm{L}( \pm 0.60))$ and $\mathrm{LDL}$ cholesterol $(0.98 \mathrm{~g} / \mathrm{L}(0.46)$ in males and $1 \mathrm{~g} / \mathrm{L}(0.49)$ in females). Furthermore, males seem have a hypoHDLemia compared with females. These differences were significant at $95 \%$ confidence level. 
Table 3. Biochemical parameters by gender in hyperglycemic patients

\begin{tabular}{|l|c|c|c|}
\hline \multicolumn{1}{|c|}{ Characteristics } & Males $(\mathbf{N}=560)$ & Females(N=531) & p_value \\
\hline Age (years) & $57.92(15.98)$ & $59.77(15.15)$ & 0.9824 \\
\hline Glucose $(\mathrm{g} / \mathrm{L})$ & $1.92(0.73)$ & $2.03(0.89)$ & 0.01012 \\
\hline Creatinine $(\mathrm{mg} / \mathrm{L})$ & $21.29(32.15)$ & $16.25(22.31)$ & $<0.0001$ \\
\hline Uric acid (mg/L) & $64.29(32.55)$ & $58.51(26.69)$ & $<0.0001$ \\
\hline Urea (g/L) & $0.71(0.72)$ & $0.58(0.57)$ & $<0.0001$ \\
\hline Total cholesterol (g/L) & $1.67(0.60)$ & $1.84(0.67)$ & $<0.0001$ \\
\hline HDL cholesterol (g/L) & $0.35(0.13)$ & $0.42(0.14)$ & $<0.0001$ \\
\hline LDL cholesterol (g/L) & $0.98(0.46)$ & $1(0.49)$ & $<0.0001$ \\
\hline Triglyceride $(\mathrm{g} / \mathrm{L})$ & $1.62(1.01)$ & $1.68(1.47)$ & 0.6213 \\
\hline eGFR $\left(\mathrm{ml} / \mathrm{min} .1 .73 \mathrm{~m}^{2}\right)$ & $77.48(42.15)$ & $91.93(47.00)$ & $<0.0001$ \\
\hline
\end{tabular}

To investigate the relationship between eGFR and biochemical parameters, we use the generalized additive model below:

$$
\begin{gathered}
\text { eGFR } \sim \alpha_{0}+\alpha_{1} f_{1}(\text { glucose })+\alpha_{2} f_{2}(\text { urea })+\alpha_{3} f_{3}(\text { calcium })+\alpha_{4} f_{4}(\text { potassium }) \\
+\alpha_{5} f_{5}(\text { triglyceride })
\end{gathered}
$$

These variables are selected by a stepwise method. The first model is a model without transformation, a generalized linear model, whereas for the second model,f_i are estimated by spline functions.

The first one explains $64 \%$ of the deviance. If we take this model with uric acid instead of urea, we have $44.5 \%$ of explained deviance. These two variables can't be used in the same model because of its collinearity. In table $\mathrm{V}$ we present results of generalized linear model. Males have a greater risk for developing a kidney disease compared to females. Urea has an important relation with the eGFR. Moreover, an increase of one unit in glucose level implies a decrease in GFR value multiplied by 8.71 . The same remark can be done for other parameters.

The model with uric acid is summarized in table VI. The triglyceride is at the limit of significance at risk level of $5 \%$. Also, the calcium has a positive effect on eGFR in this model.

The use of cubic spline allowed to identify a non-linear relation between calcium, urea, triglyceride and eGFR. The second model explains $77.2 \%$ of the deviance while the first one explains only $64 \%$ of the deviance. The adjusted coefficient $R$ is equal to 0.64 in the simple model and 0.76 for natural cubic spline model. Figure 2 shows the relationship between different predictors and GFR.

According to table VII, there is no evidence of nonlinearity for glucose variable, so we decide to include it as linear term. For other parameters, we have choose natural spline because it impose the constraint of linearity in outside of the tails. We remark that other parameters like potassium, calcium and triglyceride don't have a nonlinear effect on eGFR. The model obtained in this case is: 
Table 5. Variables effect on estimated GFR with urea

\begin{tabular}{|c|c|c|c|c|}
\hline PARAMETERS & Estimate & Se & T value & $\mathbf{P}(>\mathbf{| ~ t ~ | )}$ \\
\hline Intercept & 205.5209 & 17.2704 & 11.900 & $<2 \mathrm{e}-16$ \\
\hline Urea & -42.9316 & 2.1268 & -20.186 & $<2 \mathrm{e}-16$ \\
\hline potassium & -10.6904 & 2.5095 & -4.260 & $2.53 \mathrm{e}-05$ \\
\hline Calcium & -0.4480 & 0.1672 & -2.680 & 0.007666 \\
\hline glucose & -8.7137 & 2.6178 & -3.329 & 0.000951 \\
\hline triglyceride & -4.1004 & 1.5613 & -2.626 & 0.008952 \\
\hline
\end{tabular}

$$
\begin{gathered}
D F G \sim \alpha_{0}+\alpha_{1} \sum_{i=1}^{4} B_{i}(\text { urea })+\alpha_{2} * \text { glucose }+\alpha_{3} \sum_{i=1}^{3} B_{i}(\text { potassium })+\alpha_{4} \sum_{i=1}^{3} B_{i}(\text { calcium }) \\
+\alpha_{5} \sum_{i=1}^{3} B_{i}(\text { triglyceride }) \\
\text { lii. Dicusssion and Conclusion }
\end{gathered}
$$

Table 6. Variables effect on estimated GFR with uric acid

\begin{tabular}{|c|c|c|c|c|}
\hline PARAMETERS & Estimate & Se & T value & $\mathbf{P}(>\mathbf{| ~ t ~} \mathbf{~ )}$ \\
\hline Intercept & 184.07019 & 21.64776 & 8.503 & $3.38 \mathrm{e}-16$ \\
\hline Uric acid & -0.71797 & 0.06854 & $\begin{array}{c}- \\
10.475\end{array}$ & $<2 \mathrm{e}-16$ \\
\hline potassium & -23.60241 & 2.97037 & -7.946 & $1.83 \mathrm{e}-14$ \\
\hline Calcium & 0.59921 & 0.19252 & 3.113 & 0.00198 \\
\hline glucose & -13.97445 & 3.25327 & -4.296 & $2.17 \mathrm{e}-05$ \\
\hline triglyceride & -3.83248 & 1.95915 & -1.956 & 0.05111 \\
\hline
\end{tabular}

Table 7. Non linear effect of biochemical parameters on GFR

\begin{tabular}{|c|c|c|c|c|}
\hline Parameters & Estimate & Se & T value & $\mathbf{P}(>\mathbf{~ t ~ | )}$ \\
\hline Intercept & 149.95624 & 14.73084 & 10.180 & $<2 \mathrm{e}-16$ \\
\hline $\mathrm{ns}($ urea, 4)1 & -73.19837 & 6.54832 & -11.178 & $<2 \mathrm{e}-16$ \\
\hline $\mathrm{ns}($ urea,4)2 & -126.55307 & 8.42283 & -15.025 & $<2 \mathrm{e}-16$ \\
\hline $\mathrm{ns}($ urea,4)3 & -130.65652 & 13.55126 & -9.642 & $<2 \mathrm{e}-16$ \\
\hline $\mathrm{ns}$ (urea,4)4 & -107.51349 & 11.29973 & -9.515 & $<2 \mathrm{e}-16$ \\
\hline glucose & -6.51121 & 8.17356 & -0.797 & 0.42614 \\
\hline $\mathrm{ns}($ potassium, 3)1 & -17.20104 & 5.89575 & -2.918 & 0.00372 \\
\hline $\mathrm{ns}($ potassium, 3)2 & 0.08205 & 18.44900 & 0.004 & 0.99645 \\
\hline $\mathrm{ns}($ potassium, 3)3 & 2.73235 & 12.55371 & 0.218 & 0.82781 \\
\hline $\mathrm{ns}($ calcium, 3)1 & -19.01104 & 6.82003 & -2.788 & 0.00556 \\
\hline $\mathrm{ns}$ (calcium, 3)2 & -36.55901 & 22.73195 & -1.608 & 0.10855 \\
\hline $\mathrm{ns}$ (calcium, 3)3 & -29.41872 & 11.55790 & -2.545 & 0.01129 \\
\hline $\mathrm{ns}$ (triglyceride, 3)1 & -1.57009 & 8.22592 & -0.191 & 0.84872 \\
\hline $\mathrm{ns}$ (triglyceride, 3)2 & -30.63209 & 14.91809 & -2.053 & 0.04068 \\
\hline $\mathrm{ns}$ (triglyceride, 3)3 & -39.90629 & 18.51749 & -2.155 & 0.03174 \\
\hline
\end{tabular}

Our studied population is homogeneous in its composition. We have a quasi-equal proportion of males and females. The hyperglycemic group was older than normal group and they have no difference in the proportion of Males. Examination of the biochemical profile of our population reveals the existence of 
hyperglycemia in the one third of the studied patients. It is less than the percentage of this founded in [9]. Also, it divulge the existence of a metabolic disorder which is characterized by a dyslipidemia, hypercretininemia, hyperuricemia and hyperuremia in hyperglycemic group [10]. Precisely, patients with a higher blood glucose have a decrease in HDL cholesterol and increased triglyceride levels [11]. A higher value of uric acid induce a low eGFR so it can inform about renal function [12].

In the additive generalized model, we have eliminated variables which have a strong correlation such as uric acid. If we choose this variable instead of urea, we obtained only $44.5 \%$ of the explained deviance. This study has revealed a non-linear relation between eGFR and urea on the one hand, and between eGFR

- calcium in the other hand. Linear relation between hyperuricemia and eGFR was demonstrated in previous works[13]. Urea is used as a initial diagnosis of chronic kidney disease.

Some limits of this study, it was the fact to have a lot of missing values in our data set. So for future work, we will impute missing data. Also, this study can be extend in the future to other $\mathrm{CHU}$ in Morocco. It could be interesting to apply this study on the longitudinal data and to perform it with a local regression.

\section{REFERENCES}

[1] E. H. Baker, C. H. Janaway, B. J. Philips, A. L. Brennan, D. L. Baines, D. M. Wood, and P. W. Jones, "Hyperglycaemia is associated with poor outcomes in patients admitted to hospital with acute exacerbations of chronic obstructive pulmonary disease.," Thorax, vol. 61, no. 4, pp. 284-9, Apr. 2006.

[2] IDF, Diabetes. 2015.

[3] M. I. Harris, R. Klein, T. A. Welborn, and M. W. Knuiman, "Onset of NIDDM occurs at least 4-7 yr before clinical diagnosis." Diabetes Care, vol. 15, no. 7, pp. 815-9, Jul. 1992.

[4] C. S. Levetan, M. Passaro, K. Jablonski, M. Kass, and R. E. Ratner, "Unrecognized diabetes among hospitalized patients," Diabetes Care, vol. 21, no. 2, pp. 246-9, Feb. 1998.

[5] M. A. Tazi, S. Abir-Khalil, N. Chaouki, S. Cherqaoui, F. Lahmouz, J. E. Sraïri, and J. Mahjour, "Prevalence of the main cardiovascular risk factors in Morocco: results of a National Survey, 2000.," J. Hypertens., vol. 21, no. 5, pp. 897-903, May 2003.

[6] V. Kumar, A. K. Abbas, N. Fausto, S. L. (Stanley L. Robbins, and R. S. Cotran, Robbins and Cotran pathologic basis of disease. Elsevier Saunders, 2005.

[7] . A. Roberto Pecoits-Filho1*, Carolina C. R. Betônico3, Alisson Diego Machado2, Erika B. Parente4, Márcia Queiroz2, João Eduardo Nunes Salles4, Silvia Titan2, and and Sergio Vencio, "Interactions between kidney disease and diabetes: dangerous liaisons," Diabetol. Metab. Syndr., 2016.

[8] T. Hastie and R. J. Tibshirani, Beneralized Additive Models. Chapman \& Hall, 1990.

[9] S. Feldman-Billard, M. Joubert, R. Morello, F. Dorey, D. Seret-Begue, F. Getin-Bouyer, P. Jan, A. Colobert, E. Verlet, M. Roques, and Y. Reznik, "High prevalence of diabetes mellitus and hospital-related hyperglycaemia in French general wards," Diabetes Metab., vol. 39, no. 5, pp. 454-458, 2013. 
Souad Bechrouri, Abdelilah Monir, Hamid Mraoui, Mohamed Choukri, Ennouamane Saalaoui. Creatinine, Urea and Uric Acid in Hospitalized Patients with and Without Hyperglycemia Analysis using Generalized Additive Model. Transactions on Machine Learning and Artificial Intelligence, Vol 5 No 4 August (2017); p: 403-410

[10] E. B. Sellam and A. Bour, "Prévalence des facteurs de risque de maladies cardiovasculaires chez la femme à Oujda (Maroc)," Médecine des Mal. Métaboliques, vol. 10, no. 1, pp. 63-69, 2016.

[11] A. D. Mooradian, "Dyslipidemia in type 2 diabetes mellitus," Nat. Clin. Pract. Endocrinol. Metab, vol. 5, no. 3, pp. 150-159, Mar. 2009.

[12] B. SATIRAPOJ, O. SUPASYNDH, A. CHAIPRASERT, P. RUANGKANCHANASETR, I. KANJANAKUL, D. PHULSUKSOMBUTI, D. UTAINAM, and P. CHOOVICHIAN, "Relationship between serum uric acid levels with chronic kidney disease in a Southeast Asian population," Nephrology, vol. 15, no. 2, pp. 253-258, Mar. 2010.

[13] Y. Xu, X. Liu, X. Sun, and Y. Wang, "The impact of serum uric acid on the natural history of glomerular filtration rate: a retrospective study in the general population.” PeerJ, vol. 4, p. e1859, 2016.
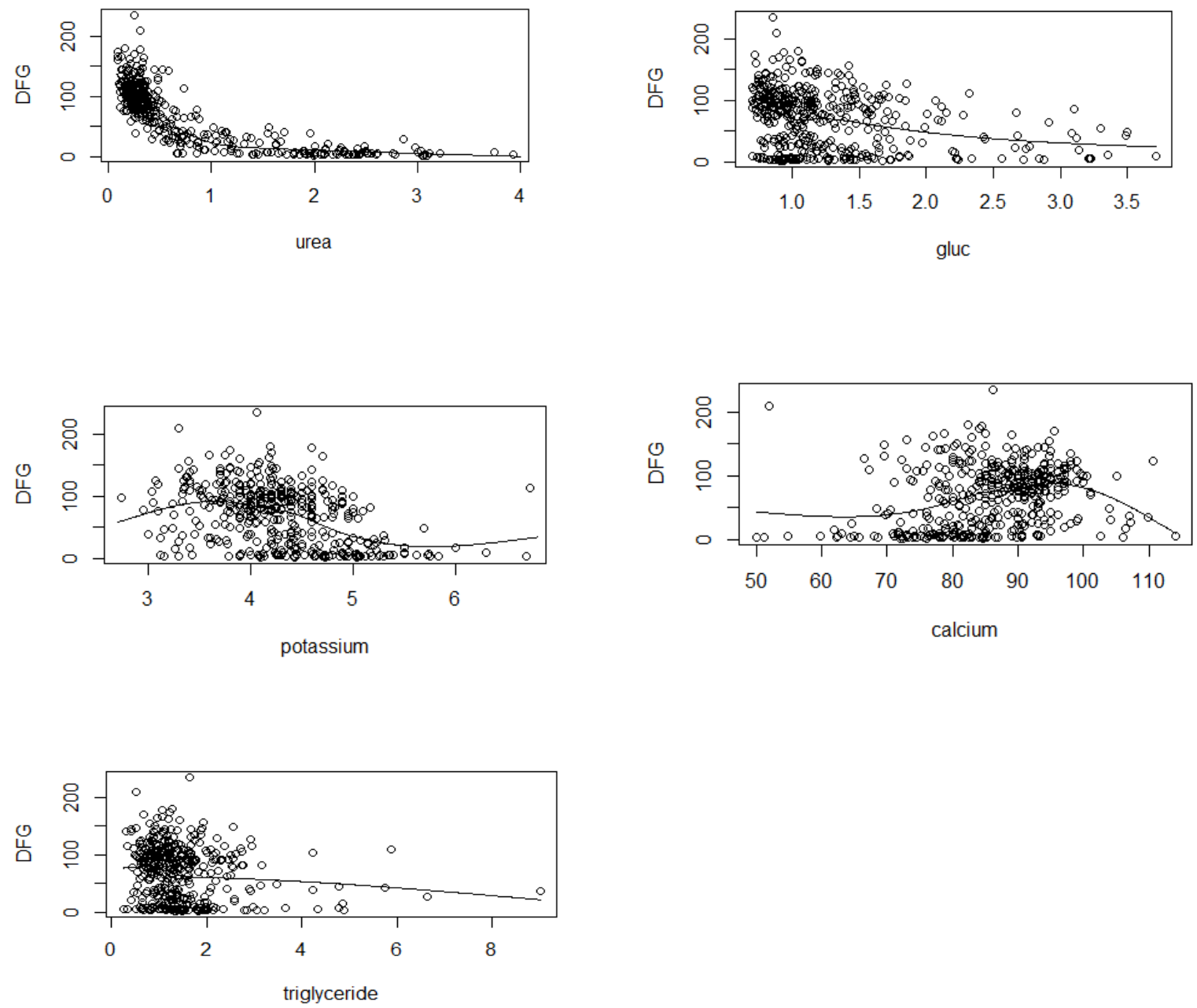

Figure 2. eGFR versus urea, glucose, potassium, calcium and triglyceride with natural spline adjustment by generalized additive regression 